\title{
Collaboration Modes and Advantages in Supply Chain
}

\author{
Lin Huang, Yong Lin, Petros Ieromonachou, Wenxian Sun ${ }^{1}$ \\ The Faculty of Business, University of Greenwich \\ London, UK \\ ${ }^{1}$ W.Sun@greenwich.ac.uk
}

\begin{abstract}
This research aims to address supply chain collaboration with a perspective of broader three-dimensional relationship, not a linear two-dimensional relationship discussed broadly in previous research. Case study was adopted for this research, and data collection was mainly conducted via interview. The research results highlighted that supply chain collaborations are common practice across all levels of the pharmaceutical supply chain. The results also indicated that the different strengthen levels of barging power among collaborative partners will influence the achieved advantages at different supply chain levels, including strategic, operational and political levels.
\end{abstract}

Keywords-Supply chain; collaboration; Pharmaceutical industry; Dyad; Triad; China

\section{INTRODUCTION}

Nowadays, competition pressures came along with the fast development of the manufacturing industries, and it accelerated the pace of globalization, the growth of production and operation costs, and an increasing number of requirements in innovation. The systematic and strategic coordination of related business functions in supply chain has been highlighted and attracts more attentions from multi stakeholders committing to achieve sustainable development in long term not only for the individual companies but also the entire supply chain as a whole.

In the past few decades, researchers and practitioners have realized that there are few factors playing important role in seeking competitive advantages. For example, achieving supply chain efficiency and responsiveness to meet the needs of markets uncertainties; maintaining the collaborative relationships with partners including not only suppliers and customers, but also government/industry agencies and research institutions, [1, 2, 3].

Within the supply chain context, collaboration can be viewed as an act of properly aligning a number of participants to achieve the common goal [4]. Although there are barriers [2, 5] of supply chain collaboration due to the issues in technology development, concepts and principles application, information sharing, and resistance to changes, a number of empirical results indicated that the collaboration has positive impact on decision-making, problem-solving, and cost-saving [4]. Comparing with the mature development of the area of supply chain management, the supply chain collaboration literature is still very limited. Moreover, current literature is lack of further explanations on the complex nature of the collaborative relationships, and some of the approaches do not consider realistic situations in actual organization [4]. From this point of view, the great potentials, importance, and value of the supply chain collaboration should be further investigated [1].

The main purpose of this paper is to investigate the impacts of supply chain collaboration on the development and performance improvement of the whole supply chain and the individual companies within the supply chain. The research objectives include identifying the models of supply chain collaboration and the advantages related with such relationships within the context of the pharmaceutical supply chain. In the followed section we will explain in detail why this research is focused on the pharmaceutical industry.

The paper is structured as below, a literature review is conducted to develop the research questions; then research methodology is discussed; the final research results will then be presented; conclusion will address the theoretical contributions, management implications, and future research directions.

\section{LITERATURE REVIEW}

\section{A. Industry Background}

The pharmaceutical industry is usually being regarded as a complex network consisting of a wide range of organizations who involved in the discovery, development, and manufacturing of the drug and medication [6], which has evolved in the past 30 years and now is with much more challenges [7]. Nowadays, the high cost in the stage of research and development (R\&D) and the declining success rate of R\&D become big challenges to pharmaceutical firms [8]. Another major challenge is the liberalized market exposes products to fierce completion. The challenge coming from government and regulatory institution is that they intend to involve more into the industry practices [6], which leads to higher pressures to companies for their further development. In order to tackle those challenges, collaboration has been regarded as one of the effective means, which has already been applied by many big pharma for a while [7]. However, for those small and medium sized enterprises (SMEs), only very few of them have started to apply collaborative strategies as the big pharma did. Even many of them may have already realized the value of supply chain collaborations to help them compete better and grow faster in the market [9]. Today's business world is rather competitive and unpredictable [5]. For one thing, SMEs are exploring ways to survive and would like to collaborate with others. For another, the complexity of 
participants in supply chain and lack of directions from experienced predecessors, which barrier the alliance [10]. Moreover, there is a serious scarce of academic resources considering the supply chain issues within the context of pharmaceutical industry, especially in supply chain collaborations. As a result, the demand on relevant researches is urgent and increasing, based on a good understanding of activities and possible requirements in collaborations, the industry in more alike to welcome prosperity.

As one of the emerging economies, China has stepped into an era of rapid growth in terms of industrialization and urbanization. Accompanied with problems as pollution of environment and aging of population, the health issues are becoming more complicated in China. The pharmaceutical sector is of course positioned in a significant place in the medical and health system and play a significant role to its development [11]. Refer to "The twelfth 5-year Healthcare Development Plan of China" [12], the government intends to further improve the national health service system with a series supports to the industry including policy and funds. In particular, it also pointed out its importance to the Chinese medicine's development. The Chinese pharmaceutical industry is largely influenced by the government and regulatory institutions when talking about shaping industry structure and building collaboration network [13]. Opportunities along with the challenges, for Chinese pharma, the high-cost in R\&D, high complexity, and long processes from "discovery" to launch to the market $[9,14]$, the shrinkage of profit margin due to the conflict between the increasing expenditures on sales and marketing [15] and related "China's retail drug price control policy" [16] are in a way slowing down the development pace of the China's pharmaceutical industry. Many companies have realized the costliness and ineffectiveness in the processes of exploring and developing [17]. In response to this, supply chain collaborations has been increasingly regarded as one of the efficient ways to generate superior performance for the whole supply chain [17]. Nevertheless, it still has a long way to go, for no one has exactly known whom to collaborate with, how to collaborate, and what they can gain from collaborations.

As an innovative industry requiring comparatively high investment in early stage of $R \& D$, there is a tendency to outsource some "noncore" activities like analytical testing and distribution logistics [9[. Moreover, outsourcing is currently a very popular management strategy which enable organizations to focus more resources on their core business [18], but it will introduce more participants coming from different professional areas into the pharmaceutical supply chain. The collaboration is becoming an even more complex topic. Thus, it is meaningful to summarize the collaboration modes and roles in pharmaceutical supply chain, not only to benefit China's pharmaceutical industry, but also helpful in providing guidance for pharma around the world and their supply chain partners to further develop in a sustainable way.

\section{B. Supply Chain Outsourcing}

Supply chain can be regarded as a series of activities and organizations facilitating physical material flow from the raw materials suppliers to the end consumers [19]. Through close integration of the internal functions and effective linkage with their external operations, supply chain collaboration is usually expected to help firms enhance their competitive performance [2]. The pharmaceutical manufacturer as one of the main players in the healthcare supply chain [20], has critical role in connecting other players in the supply chain, such as only the not only suppliers and direct customers, but also the government, regulatory institutions, delivery networks, and other channel members in pharmaceutical supply chain $[6,7$, $11]$.

After broadly reviewing recent literatures, previous researches on dyads are mainly focused on the downstream network, but the upstream issues related with $R \& D$, procurement, production, and supply management are considered separately [21]. To achieve a successful and efficient management of the pharmaceutical supply chain, it cannot simply rely on those separate efforts from some individual participants in the supply chain [5]. Hence, the main concern here is how to collaborate with those independent actors in the supply chain to reach an acceptable common goal [4] in particular in such a changing market. With the multiple linkages among trading partners and even third parties, a wellmanaged pharmaceutical supply chain can be a competitive weapon [9].

By moving some of the organizational activities to outside vendors [22] in order to get competitive advantages in terms of cost-saving and resource-leverage [23], outsourcing is increasingly accepted and applied by manufacturers in many industries. Manufacturers in the pharmaceutical industries are usually being considered as an innovative enterprise [8], which needs to face significant challenges of high $R \& D$ costs but with low success rate, and pressures in declining the time to market for high margins to ensure the significant investment in $R \& D$ [24]. R\&D as the core activity was once fully controlled and fed by pharmaceutical companies. In order to apply the most resources to focus on it, manufacturers tended to outsource some non-core and maybe non-value-added activities to third parties [9].

However, the situation is under changing; it has never before been available for pharmaceutical industry in outsourcing, due to the rise scientifically competent and manufacturing flexibility [25]. Outsourcing strategy has been applied not only limited to non-core activities, but also the core activities such as R\&D and manufacturing have been involved as well (see Table I), which may lead to heavily collaboration in public science [26]. Moreover, as highly productive R\&D requires huge investment, flexible strategic alliance with peer competitors is needed as an effective outsourcing tool to mitigate risks $[27,28]$.

Outsourcing in pharmaceutical supply chain is frequently discussed in the processes of: (1) R\&D [20, 23, 25], which benefits in cost-reduction, opportunity-creation, and sustainable development; (2) Manufacturing [20, 21, 29], which increases the flexibility while remaining competitiveness on cost and quality; (3) Logistics [9, 30, 31], which enables resource leverage and further performance improvement. In outsourcing, although the internal activities and decision responsibilities have been fully or partly turned over, the elaborate network of 
buyer-supplier (outsourcing provider) will be developed [32]. The supply chain collaborations are indispensable [33], if done properly, the strategic outsourcing alliance can help to achieve a sustainable development for the pharmaceutical organizations in the supply chain.

TABle1 I. Percentage OF SUPPly CHAIN ACTIVITIES OUTSOURCED IN PHARMACEUTICAL INDUSTRY

\begin{tabular}{|c|c|r|}
\hline \multicolumn{2}{|c|}{ Outsourcing function } & \multicolumn{2}{c|}{ Leaders } \\
\hline Enabler & New product development & $50 \%$ \\
\hline \multirow{3}{*}{ Plan } & Demand planning & $8.5 \%$ \\
\cline { 2 - 3 } & Sales and Operations planning & $0 \%$ \\
\hline \multirow{2}{*}{ Source } & Strategic Procurement & $17 \%$ \\
\cline { 2 - 3 } & Operational Procurement & $0 \%$ \\
\hline \multirow{2}{*}{ Deliver } & Manufacturing and Assembly & $50 \%$ \\
\cline { 2 - 3 } & Inbound and outbound logistics & $33 \%$ \\
\cline { 2 - 3 } & Warehousing & $42 \%$ \\
\cline { 2 - 3 } & Customer Order desk & $42 \%$ \\
\cline { 2 - 3 } & & $42 \%$ \\
\hline
\end{tabular}

\section{Supply Chain Collaboration}

As a potential key of creating value, collaboration in supply chain is prevailing and growing. Participants come from various individual businesses across sectors are involved in different level. The increasingly complex environment brings about possible mess, where crisis is around the corner. To figure out certain modes of collaboration and further investigate their impacts on supply chain performance is imperative. Supply chain collaboration is usually described as a collective process/activities which depend on the interactions and relationships of participant stakeholders, which included suppliers, manufacturers, customers, government agencies, research institutions/universities, third party service provider, and even competitors. It has been emphasized that relational means and contract means [1] from governance will enable collaborative partners to gain sustainable benefits jointly in the supply chain [34].

Within a pharmaceutical supply chain, there are some players directly associating with pharmaceutical manufacturer, these include material-medical suppliers, wholesalers, distributors (integrated delivery networks, including 3PLs), customers (including hospitals and physicians), academia (including university and research institutions), government, and regulatory institutions [3, 13, 17, 20, 35, 36]. Furthermore, the manufacturing outsourcing and partners acquisition may also involve subcontract partners and subsidiaries into the supply chain [25].

Collaboration in supply chain invites organizations across different sectors to join in to complete certain projects mutually that based on the same interests. To better understand the collaboration, it is important to identify the partners' motivation that drive organizations to involve, as it could further impact on their collaborative behaviors on a large degree. The driving forces for alliance creation include motivations of cost-reduction [33] [33, 37, 38], flexibility [22], sustainability [39], and also future opportunity [6, 40]. Meanwhile, with the increasingly intervene coming from the government and regulatory institutions [6], maintain good relationship with the political players becomes import to get required supports for expansion and also for better development. The possible collaborations are tied to different levels covering from operation, strategy, to policy [41.

The relationship theories existed are mostly based on dyadic views. The dyadic relationships wildly discussed in supply chain management are "supplier-buyer" and "suppliersupplier". In the previous researches, has not been fully discovered on the complexity of the dyadic collaborative relationship [4], there is scare of related references of collaborative modes. Although the starting point and final expectation alliance are positive, it is still a big challenge to empirically identify the exact benefits of collaborations [5] in different realistic situations [4].

\section{Research Framework}

Refer to the review above, ten dyadic relationships (see Fig 1) between the focal company and possible partners will be investigated based on the driving forces, including motivations of cost-reduction, flexibility, sustainability, opportunity, and policy \& regulation.

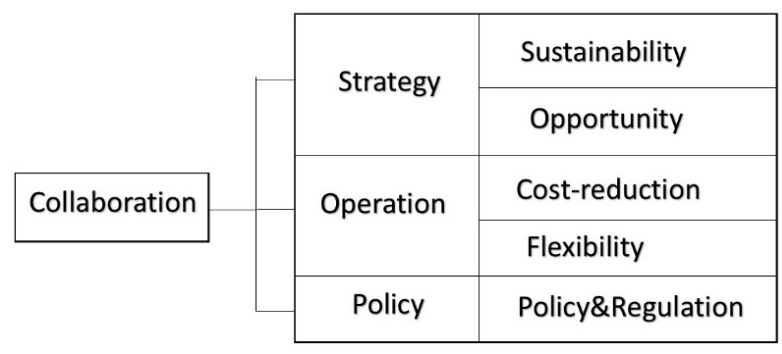

Fig. 1. Conceptual research framework

The research questions defined in this research are,

Q1: How different modes of supply chain collaboration formed in the pharmaceutical supply chain?

Q2: How different modes of supply chain collaboration influence the performance?

\section{RESEARCH METHODOLOGY}

Literature review is made to identify the gaps in research area. Research questions are generated based on the review. Concepts related to the synonyms of collaborations frequently appeared in researches of supply chain management has been clarified; and a conceptual framework has been created refer to the result. Case study is adopted as the research method to answer the defined research questions.

\section{A. Case Study}

In this research, realistic situation [4] is considered, which makes the explanations to be quite complex and may cover an extended period of time. The research questions proposed are mainly defined as "what" and "how", a case study is appropriate as the research methodology [42]. The multiple case study is preferred. To get general collaboration modes, the involvement of samples from more than one industry could in a way reduce the bias may be caused by single case study.

Case companies are selected in regarding to the industry factor (Traditional manufacturing industry and innovative manufacturing industry), firm size (small-to-medium sized 
enterprise), and region (China mainland). Three cases PM-1, PM-2, and PM-3 have been studies in this research.

\section{B. Data Collection}

Multiple sources of date are used to address broader range of validity issues [42], which included data collected through field visits, semi-structural interviews, questionnaires, and secondary documentation. Data applied to this study is mainly collected via interview and questionnaire survey.

The two-stage process is designed for data collection. In stage one, a 1-2 hour(s) interview were organized with the top manager at first, and then with department managers (operation manager, production manager, logistic manager) would be individually interviewed. In stage two, referring to the results collected in stage one, a questionnaire is designed and send to the assistant of the top manager, and the assistant will contact the department managers to complete it.

\section{Data Analysis}

Pattern matching strategy is adopted to analyze the collected to verify the supply chain collaboration modes and impacts following the conceptual framework as described in Fig. 1. Compare to a single case study, the result generated by multiple-case studies will be more robust. A number of case studies are required for this research, there are differences in different set of companies in business practice [36]; the multiple-case studies are more alike be able to explore specific phenomenon in details.

\section{ANALYSIS AND FINDINGS}

\section{A. Decisive Fators to Supply Chain Collaboration Modes}

The research results shown that supply chain collaboration modes are largely depends on the activities outsourced. Moreover, the results have indicated that $\mathrm{R} \& \mathrm{D}$ and logistics are two activities being outsourced frequently in the pharmaceutical industry.

In PM-1 and PM-2, there are ten dyadic relations have been confirmed, but in PM-3, there are only seven relation modes existed. The reason of the relatively low number is mainly due to that PM-3 is a pharmaceutical focus on patented traditional Chinese medicine. Moreover, its number of product category and the scale of production volume is also small.

The outsourcing R\&D is normally in the form of commissioned and joint researches with the actors in the pharmaceutical manufacturing supply chain, such as research institutions, and even competitors. In general, R\&D as a traditional core activity, outsourcing occurs when sufficient funds used to support the outsourcing is guaranteed [32] in the big pharma. However, in order to achieve sustainable development and cost-saving, those SMEs intend to partly outsources R\&D activity. Furthermore, in order to ensure the achievement of mutual benefits, focal company intends to define partner in several perspectives, for example expertise and experience, references and industry vision [41]. The wellestablished relationship between focal company and outsourced partners is more than just buyer-supplier, but more alike alliance in the supply chain.

The logistics has also becoming one of the key activities that focal companies planned to outsource it out to third parties. But different from the big pharma in the developed economies [38], the logistics outsourcing has not reached a strategic level [31]. As a result, many of SMEs in China still prefer to only outsource non-core activities like inventory management to third party. One reason for that is the cost and shortage of professional 3PLs in the market. Moreover, the focal company are relied heavily on their 3PLs, but the switching costs are low, which gives pharmaceutical manufacturer more negotiation power in the relationship.

With different focus of the activities outsourced, various collaboration modes will be formed in the industry to achieve targeted benefits. Following sections will discuss the possible modes and its impacts on supply chain performance.

\section{B. Modes of Supply Chain Collaboration}

The modes of relation addressing in the different phases of a pharmaceutical supply chain has been developed in Fig. 2 .

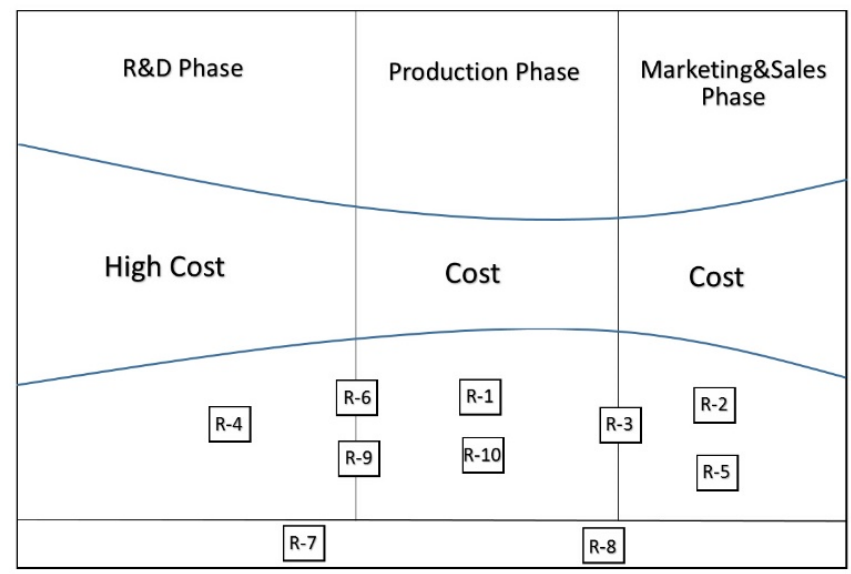

Fig. 2. Collaborative relation modes

The creation of certain collaborative relation is motivated by different factors at different levels [41]. For $\mathrm{R} \& \mathrm{D}$, the collaborations are normally happened in all phases (Fig. 2), which are expected to gain specific advantages at its phases. As a channel to gain resources, information, and knowledge, Guanxi could help firms to facilitate the achieving of anticipated performance and to enhance the opportunity of achieving mutual benefits.

One interesting thing is the importance of networking with government and regulatory institutions. In short term, it may not bring direct benefits in. but in a long term, it will deliver advantages to operational level if build a strategic collaboration focusing on sustainability and future opportunity. The other interesting thing from the results is that, collaborating with academia seems to has less risk and has more potential to gain advantages in the market [32]. 


\section{Impacts of Supply Chain Collaboration}

If partners' barging power is fairly equal, the formation of strategic alliance will enable pharmaceutical manufacturer to gain more opportunities for accessing resources, knowledge, and information. Meanwhile, the focal company and its partner can anticipate a sustainable development in near future.

If the barging power is not equal, the relationship will more like a simple form of buyer-supplier. In this situation, focal company usually focuses on achieving realistic benefits such as cost-saving and flexibility. Obviously the relationship is more stay at an operational level. Once the barging power becomes equal among partners, the possibility to gain cost-saving is somehow decreasing, however, the flexibility still can be guaranteed.

The results indicated that the function of the supports of fund, policy, and regulation-support is very limited in achieving cost-reduction. In responding to the market change, the flexibility is actually not high in this situation. Meanwhile, those SMEs are more sensitive to the political actions.

\begin{tabular}{|c|c|c|}
\hline \multirow{2}{*}{$\begin{array}{c}\text { Strategic } \\
\text { Collaboration }\end{array}$} & General Equilibrium & $\begin{array}{c}\text { Barging Power } \\
\text { (strong in focal company) }\end{array}$ \\
\cline { 2 - 3 } & $\begin{array}{c}\text { Sustainability } \\
\text { Opportunity }\end{array}$ & $\begin{array}{c}\text { Most advantages obtain in } \\
\text { Operational level }\end{array}$ \\
\hline $\begin{array}{c}\text { Operational } \\
\text { Collaboration }\end{array}$ & Flexibility & $\begin{array}{c}\text { Cost-saving } \\
\text { Flexibility }\end{array}$ \\
\hline Political & N/A in SMEs & $\begin{array}{c}\text { Focal companies (SMEs are } \\
\text { always in comparatively weak } \\
\text { Collaboration }\end{array}$ \\
\end{tabular}

Fig. 3. Collaboration and advantage matrix

Although there are many advantages can be achieved through collaborations, some joint supply chain risks are also possibly existed. In the version of PM-3, some significant differences indicate the potential collaborative issues in China's pharmaceutical supply chain, which is waiting for further analysis.

\section{CONCLUSION}

This research tried to identify the modes of supply chain collaboration at strategic, operational, and policy level. Furthermore, it discussed certain advantages that collaborations may bring about and how they will influence the performance of a pharmaceutical supply chain.

The limitation of the research is mainly within the methodology part, only 3 case studies are involved, and the pattern impacts are investigated and summarized in general. The Chinese patent medicine manufacturing is increasingly concerned by political institution, and the research result shows there is quite a bit different when compare with common pharmaceutical manufacturing in both modes and the collaboration impacts. In the future, data will be collected more in pharmaceutical industry and especially in the area of Chinese patent medicine manufacturing. Moreover, the empirical research on this specific topic could be extended to other cultural and country backgrounds to conduct a comparative studies in the future; in this way, a more practical model is expected.

\section{REFERENCES}

[1] Cao, M. and Zhang, Q., "Supply Chain Collaboration: impact on collaborative advantage and firm performance". Journal of Operation Management, vol. 9, no. 3, pp. 163-180, 2011.

[2] Liao, S.-H. and Kuo, F.-K., "The Study of Relationships between the Collaboration for supply Chain, Supply Chain Capabilities and Firm Performance: a case of the Taiwan's TFT-LCD industry". International Journal of Production Economics, vol. 156, no. 1, pp. 295-304, 2014.

[3] Kafouros, M., Wang, C., Piperopoulos, P. and Zhang, M., "Academic Collaborations and firm innovation performance in China: the role of region-specific institutions". Research Policy, vol. 44, no. 3, pp. 803$817,2015$.

[4] Montoya-Torres, J.R. and Ortiz-Vargas, D.A., "Collaboration and Information Sharing in Dyadic Supply Chain: a literature review over the period 2000-2012". Estudios Gerenciales, vol. 30, no. 133, pp. 343354, 2014.

[5] Ramanathan, U., "Performance of Supply Chain Collaboration - a simulation study". Expert Systems with Applications, vol. 41, no. 1, 210220, 2014.

[6] Shah, N., "Pharmaceutical Supply Chains: key issues and strategies for optimization". Computers and Chemical Engineering, vol. 28, no. 6-7, pp. 929-941, 2004.

[7] Forster, S.P., Stegmaier, J., Spyher, R. and Seeger, S., "Virtual Pharmaceutical Companies: collaborating flexibly in pharmaceutical development”. Drug Discovery Today, vol. 19, no. 3, pp. 348-355, 2014.

[8] Laínez, J.M., Schaefer, E. and Reklaitis, G.V., "Challenges and Opportunities in Enterprise-wide Optimization in the Pharmaceutical Industry". Computers and Chemical Engineering, vol. 47, pp. 19-28, 2012.

[9] Rees, H., "Supply Chain Management in the Drug Industry". John Wiley \& Sons, Inc, 2011.

[10] Koh, R., Schuster, E.W., Chackrabarti, I. and Bellman, A., "White Paper: securing the pharmaceutical supply chain". Auto-ID Centre, MitAutoID-WH-21, 2003.

[11] Yu, X., Li, C., Shi, Y. and Yu, M., "Pharmaceutical Supply Chain in China: current issues and implications for health system reform". Health Policy, vol. 97, no. 1, pp. 8-15, 2010.

[12] The state council of the People's Republic of China, "The twelfth 5-year Healthcare Development Plan of China”. http://www.gov.cn, 2012.

[13] Yu, Y., Ma, Z., Hu, H. and Wang, Y., "Local Government Policies and Pharmaceutical clusters in China". Journal of Science and Technology Policy Management, vol. 5, no. 1, pp. 41-58, 2013.

[14] Huang, S., "How can innovation create the future in a catching-up economy? Focusing on China's pharmaceutical industry". Journal of Knowledge-based Innovation in China, vol. 4, no. 2, pp. 118-131, 2012.

[15] PricewaterhouseCoopers, "Pharma 2020: The vision which path will you take? Pharmaceutical and life sciences". http://www.pwc.com/gx/en/pharma-life-sciences/pharma-2020/pharma2020-vision-path.jhtml, 2007

[16] Meng, Q., Cheng, G., Silver, L., Sun, X., Rehnberg, C. and Tomason, G., "The Impact of China's Retail Drug Price Control Policy on Hospital Expenditures: a case study in two Shandong hospitals". Health Policy and Planning, vol. 20, no.1, pp. 185-196, 2005.

[17] Zhang, M., Pawar, K.S., Shah, J. and Mehta, P., "Evaluating Outsourcing Partners' Capability: a case study from the pharmaceutical supply Chain". Journal of Manufacturing Technology Management, vol. 24, no. 8, pp. 1080-1101, 2012. 
[18] Abudul-Halim, H., Ahmad, N.H. and Ramayah, T., "Unveiling the motivation to outsource among SMEs". Business Strategy Series, vol. 13, no. 4, pp. 181-186, 2015.

[19] Bales, R.R., Maull, R.S. and Radnor, Z., "The development of supply chain management within the aerospace manufacture". Supply Chain Management: An International Journal, vol. 9, no. 3, pp. 250-255, 2004.

[20] Pedroso, M.C. and Nakano, D., "Knowledge and Information Flows in Supply Chains: a study on pharmaceutical companies". International Journal of Production Economics, vol. 122, no. 1, pp. 376-384, 2009.

[21] Narayana, S.A., Pati, R.K. and Vrat, P., "Managerial Research on the Pharmaceutical Supply Chain - a critical review and some insights for future directions". Journal of Purchasing and Supply Management, vol. 20, no. 1, pp. 18-40, 2014

[22] Scherre-Rathje, M., Deflorin, P. and Anand, G., "Manufacturing Flexibility through Outsourcing: effects of contingencies". International Journal of Operations and Production Management, vol. 34, no. 9, 1210-1242, 2014.

[23] Boulaksil, Y. and Fransoo, J.C., "Implications of Outsourcing on Operations Planning: findings from the pharmaceutical industry". International Journal of Operations and Production Management, vol. 30, no. 10, pp. 1059-1079, 2010.

[24] Sousa, R.T, Shah, N. and Papageorgiou, L.G., "Global Supply Chain Network Optimisation for Pharmaceuticals". Computer Aided Chemical Engineering, vol. 20, pp. 1189-1194, 2005.

[25] Scarlett, J.A., "Outsourcing Process-development and Manufacturing of rDNA-derived Products". Trends in Biotechnology, vol. 14, no. 7, pp. 239-244, 1996.

[26] Lim, K., "The Relationship between Research and Innovation in the Semiconductor and Pharmaceutical Industries" (1981-1997). Research Policy, vol. 33, no. 2, pp. 287-321, 2004.

[27] Takayama, M., Watanabe, C. and Griffy-Brown, C., "Alliance strategy as a competitive strategy for successively creative new product development: the proof of the co-evolution of creativity and efficiency in the Japanese pharmaceutical industry". Technovation, vol. 22, no. 10, 607-614, 2002.

[28] PricewaterhouseCoopers, "Ensuring Pharmaceutical Supply Chain Effectiveness, Pharmaceutical and Life Sciences". http://www.pwc.com/gx/en/pharma-life-sciences/supply-chaineffectiveness/index.jhtml, 2012

[29] Agarwal, "Chemistry and Integrated Services in Emerging Countries: how is the pharmaceutical value chain changing with companies demanding chemistry and a provider in emerging countries and what are suppliers doing to upgrade the offerings and mitigate the business risk?". Drug Discovery Today, vol. 17, no. 23-24, pp. 1251-1253, 2012.

[30] Zhou, E.Y., "China Today - pharmaceutical distribution in China: the country strive to modernize its distribution logistics as thousands of small companies compete for profits". Biopharm International, vol. 20, pp. 8-24, 2007.

[31] Azzi, A., Persona, A., Sgarbossa, F. and Bonin, M. (), "Drug Inventory management and Distribution: outsourcing logistics to third-party providers". Strategic Outsourcing: An International Journal, vol. 6, no. 1, pp. 48-64, 2013.

[32] Spithoven, A. and Teirlinck, P., "Internal Capabilities, Network Resources and Appropriation Mechanisms as Determinants of R\&D Outsourcing". Research policy, vol. 44, no. 3, pp. 711-725, 2015.

[33] Baloh, P., Jha, S. and Awazu, Y., "Building Strategic Partnerships for Managing Innovation Outsourcing". Strategic Outsourcing: An International Journal, vol. 1, no. 2, pp. 100-121, 2008.

[34] Sahay, B. S., "Supply Chain Collaboration: the key value creation2. Work Study, vol. 52, no. 2, pp. 76-83, 2003.

[35] Hira, A., "The political economy of the global pharmaceutical industry: why the poor lack access to medicine and what might be done about it". International Journal of Development Issues, vol. 8, no. 2, pp. 84-101, 2009.

[36] Conle, M. and Taube, M., "Regional Specialization in China's Biopharmaceutical Industry". Chinese Management Studies, vol. 4, no. 4, pp. 339-359, 2010.

[37] Lau, K.H. and Zhang, J., "Drivers and Obstacles of Outsourcing Practices in China". International Journal of Physical Distribution and Logistics Management, vol. 36, no. 10, pp. 776-792, 2006.

[38] Größler, A., Laugen, B. T., Arkader, R. and Fleury, A. (), "Differences in Outsourcing Strategies between Firms in Emerging and Developed Markets". International Journal of Operation and Production Management, vol. 33, no. 3, pp. 296-321, 2013.

[39] Elango, B., "Using Outsourcing for Strategic Competitiveness in Small and Medium-sized Firms". Competitiveness Review: An International Business Journal, vol. 18, no. 4, pp. 322-332, 2008.

[40] Rapp, A., "Outsourcing the Sales Process: hiring a mercenary sales force". Industrial Marketing Management, vol. 38, no. 4, pp. 411-418. 2009.

[41] Whitworth, M., "Outsourced Security - the benefits and risks". Network Security, vol. 10, pp. 16-19, 2005.

[42] Yin, R.K., "Case Study Research: Design and Methods (5 ${ }^{\text {th }}$ Edition)". SAGA Publications, Inc., 2014. 